\title{
Use of the bio-engineering technologies in the construction and upgrade of complex installations for obtaining energy from three renewable sources. Complex installations for flowing waters
}

\author{
George Poteraș ${ }^{1}$, György Deák ${ }^{1}$, Iasmina-Florina Burlacu ${ }^{1,}$, Simona Natalia Raischi $^{1}$, and \\ Violeta-Monica Radu$^{1}$ \\ ${ }^{1}$ National Institute for Research and Development in Environmental Protection, 294 Splaiul \\ Independentei Blv, 060031, Bucharest, Romania
}

\begin{abstract}
In the context of the sustainable development, the problem of the widespread use of renewable energy resources, which are clean and inexhaustible, is becoming more acute. In this regard, it is necessary to develop some capture installations that use renewable energy sources as efficiently as possible and with low impact on the environment. This paper presents a patented installation that integrates three sources of renewable energy: wind energy, solar energy and hydraulic energy of water current. The efficiency of this complex installation is given by the fact that the simultaneous capitalization of the three renewable energy sources leads to a high efficiency, in relation with the occupied area. To increase the renewable energy absorption level, both the air turbine and the hydraulic turbine have been equipped with different bioengineering models of blades and paddles. Following the testing of the two turbines equipped with blades and paddles with bioengineering geometry, a significant improvement of their efficiency was found, compared to the initial blades and paddles.
\end{abstract}

\section{Introduction}

There are mainly three potential renewable energy sources on the flowing waters, which can be converted into electricity: water energy, wind energy and solar energy.

The energy of water currents which practically represents an inexhaustible renewable energy source, is having several advantages as it follows is non-polluting, does not presents difficulties in operation and energy is stored in the network of flowing waters which covers a significant area of the Earth's surface.

Wind energy, which is ranked on second place in terms of electricity production efficiency, after energy produced by the hydropower plants, is an important source of renewable energy, but the wind farms occupy important areas of land and have an impact

\footnotetext{
*Corresponding author: iassminaa@yahoo.com
} 
on both the landscape and on ecosystems. Over the riverbeds, the wind energy is enhanced by the intensity of the air currents, which is manifested in a favourable regime, in terms of duration and intensity.

Solar energy is an intermittent source of energy due to day-night alternations, and its efficient use requires the development of adequate storage systems, capable of efficiently storing this energy. In flowing waters, solar energy is significantly amplified by the light reflection phenomena.

All these features of the renewable energy sources are arguments that demonstrate the need to develop complex installations that integrate the three natural resources and which capitalize, with maximum efficiency, the clean energies provided by the environment, thus reducing the negative effects induced by greenhouse gas emissions from the atmosphere, as a result of the use of energy produced through conventional methods. To this end, the EU has set a target to increase the share of energy from renewable sources to at least $32 \%$ [1].

As the separate use of the three renewable energy sources involves the arrangement of considerable areas, which have a significant impact on the aquatic environment, the production of renewable energy in the integrated system, with vertical development, eliminates this important disadvantage. At the same time, the simultaneous capitalization of the three potential renewable energy sources into an integrated system has, in relation with classic installations, the highest efficiency per unit area.

The present paper has as starting point a patented invention, an installation for the production of electricity from 3 renewable sources [2] and aims to improve the efficiency of the installation by applying bioengineering solutions to the achievement of the wind turbine and hydraulic turbine blades and paddles, as a part of the TEACHERS project [3].

The scientific literature presents the advances made in the technical stage of the development of the integrated renewable energy production systems and their advantages in relation with the conventional electricity production systems [4]. A similar installation to the one presented in this paper is the hybrid turbine that converts wind and solar energy into electricity and whose dimensions reduce the surface area of the terns [5]. Moreover, there are also other installations using renewable energy sources for electricity production [6].

\section{Methodology}

Installations that integrate several renewable energy sources to obtain electricity are compact and can be used with success in flowing waters due to their kinetic potential. They can provide electricity for activities that take place in the adjacent areas and/or over the flowing waters, as well as in hard-to-reach areas.

\subsection{Description of the initial installation}

The complex installation for the production of electricity from three renewable energy sources (water energy, wind energy and solar energy) consists of two distinct modules: a cylindrical aerial module, which captures both the energy of air currents and solar energy and a partially submerged cylindrical module, which captures hydraulic energy. At the intersection of the axis of the air module with the axis of the partially submerged module, a coupling of multiplication and transmission of the rotation speed is provided. On the central axis of the air module there are 8 rows of trapezoidal blades arranged in an extension of the other and in perpendicular planes. The cylinder generators are provided vertical slots for concentrating the air flow, adjustable by a system of deflectors, which also have the role of support for photovoltaic cells.

The partially submerged module has cylindrical shape and the same diameter as the air module being immersed in water so that the horizontal axis does not come into contact with 
water. On the horizontal axis of the module are provided 16 rectangular paddles, grouped 8 on each side of the coupling system. On the cylinder generator are provided 6 horizontal slots in the submerged area and two symmetrical slots, above the axis. At the same time, the partially submerged module is provided with 2 manholes.

The submerged part of the module and the assembly consisting of the air module and the part of the partially submerged module, which is above the water, are fixed on a floating platform on which are located spaces for carrying out various activities. The complex for producing energy from renewable sources in flowing waters can have various dimensions, depending on the characteristics of the watercourse in which it is located and can be fixed or mobile, being provided with anchoring systems and devices that allow its towing. The electricity transformation and storage equipment is located in the technological space of the floating platform [2].

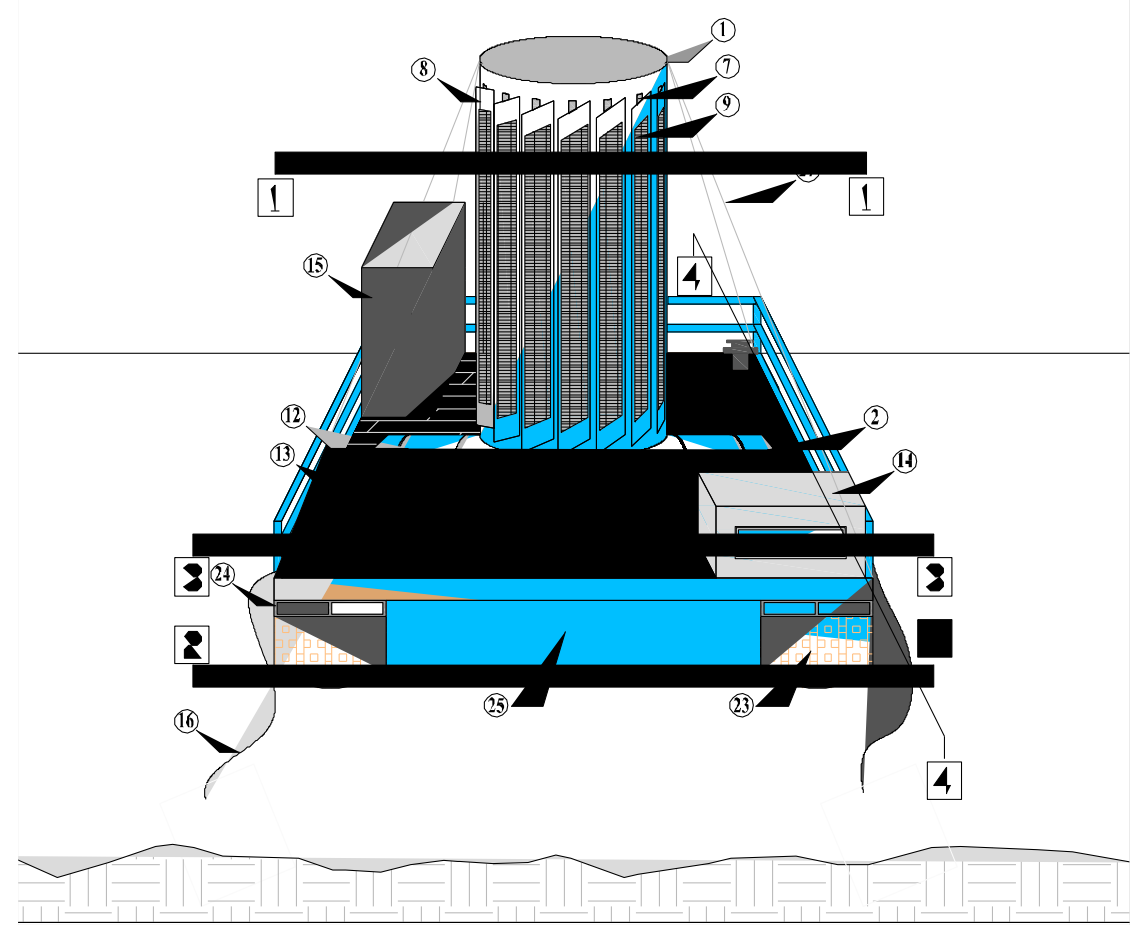

Fig. 1. Complex installation for the production of renewable energy in flowing waters

1 - The aerial module; 2 - Partially submerged module; 3 - Vertical axis of the aerial model; 4 Horizontal axis of the partially submerged model; 5 - Coupling for multiplication and transmission of rotational motion; 6 - Trapezoidal blades; 7 - Slot with an opening of $0.10 \mathrm{~m}$ and $4.50 \mathrm{~m}$ length; 8 Deflector with 0.25 - $0.30 \mathrm{~m}$ width and $4.8 \mathrm{~m}$ length; 9 - Photovoltaic cells; 10 - Rectangular paddle with $1.00 \mathrm{~m}$ width and $2.20 \mathrm{~m}$ length; 11 - Slot with an opening of $0.13 \mathrm{~m}$ and $4.50 \mathrm{~m}$ length; 12 Visiting and intervention box; 13 - Floating platform; 14 - Technological space; 15 - Research space; 16 - Anchoring system for the floating platform; 17 - Cassette with axial bearings; 18 - Pressure bearing box; 19 - Gear speed multiplier; 20 - Blade clamping system - vertical central axis; 21 Deflector clamping system; 22 - Paddle clamping system - horizontal central axis; 23 - Floats; 24 Metal frame for fixing floats; 25 - Protection grille; 26 - Partially submerged module clamping system - floating platform; 27 - Air module anchoring system - floating platform. 

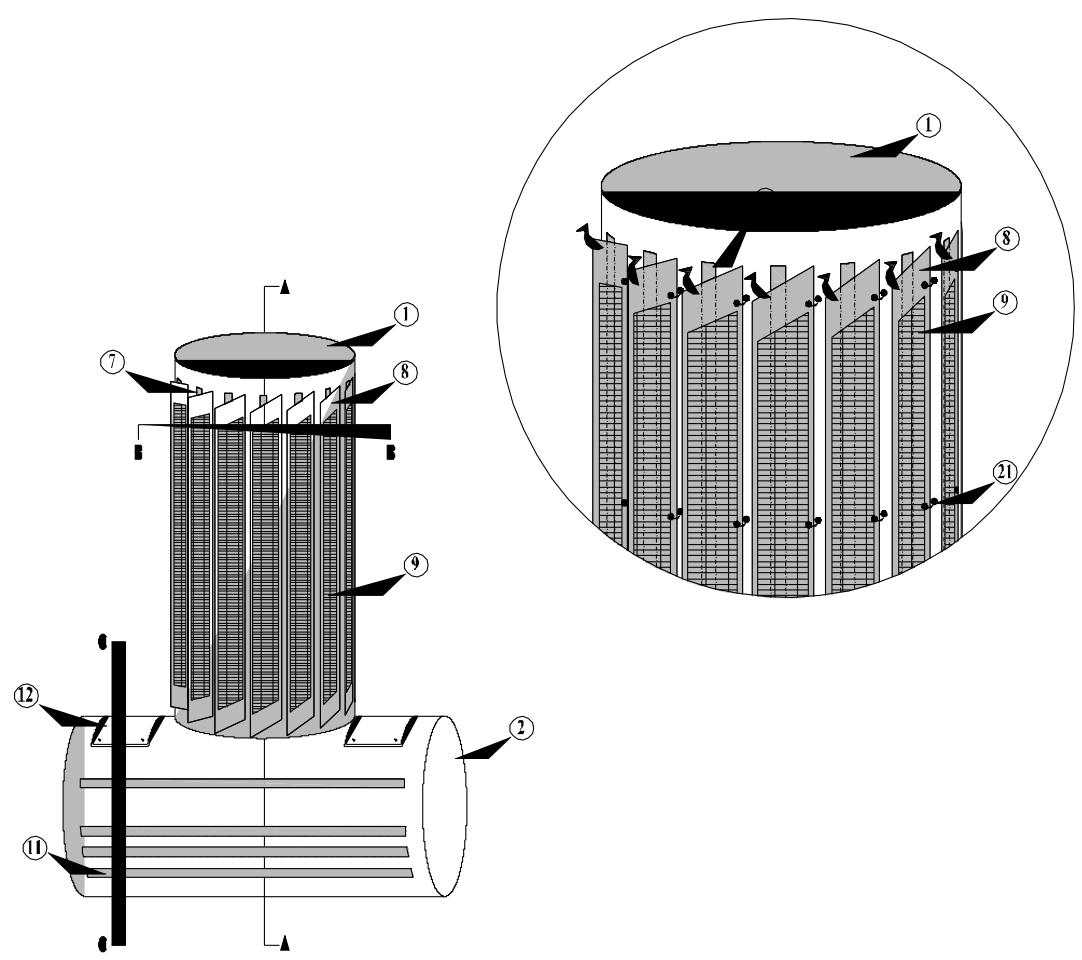

Fig. 2. Complex installation for the production of renewable energy in flowing waters - Deflector detail

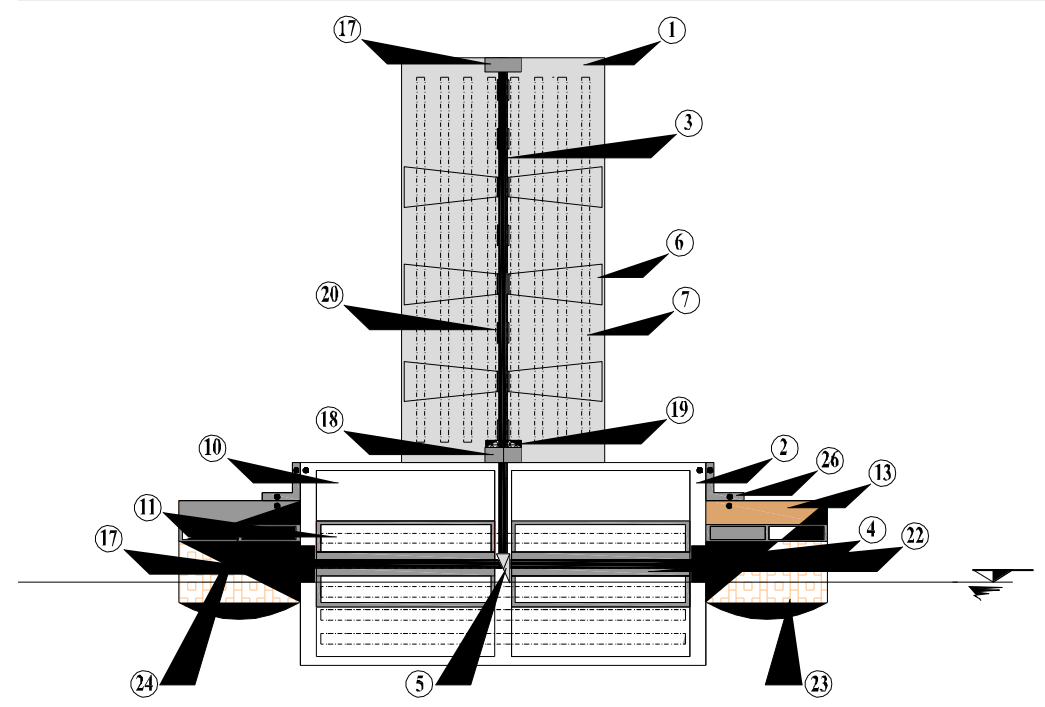

Fig. 3. Complex installation for the production of renewable energy in flowing waters - Section A-A 


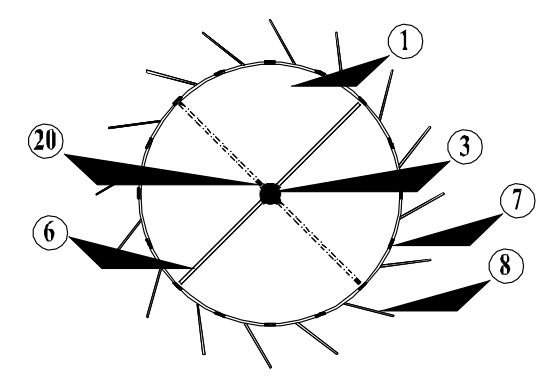

Section B-B

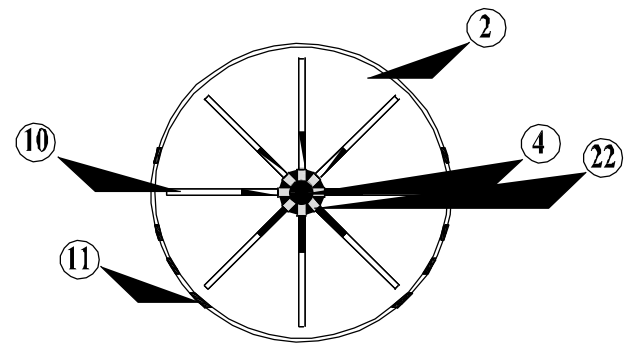

Section C-C

Fig. 4. Complex installation for the production of renewable energy in flowing waters

The geometry of the blades and paddles is shown in the figure 5:

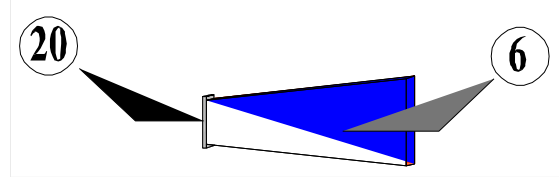

a)

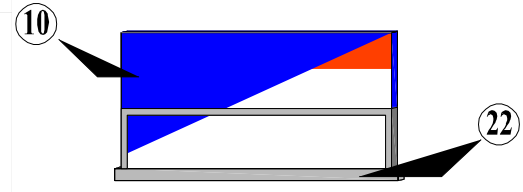

b)

Fig. 5. Complex installation for the production of renewable energy in flowing waters - Detail: a) trapezoidal blades; b) rectangular paddles

The shape of the floating platform is shown in the figure 6 :

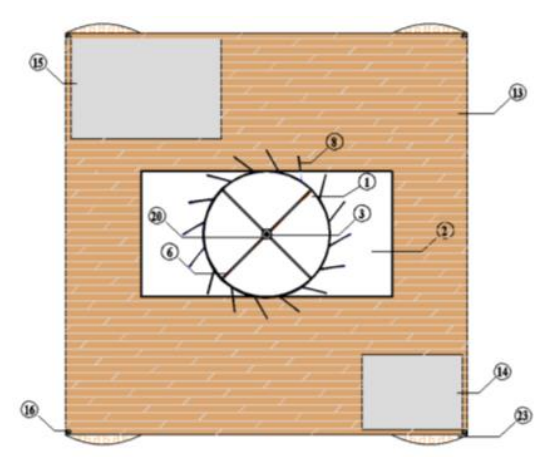

a)

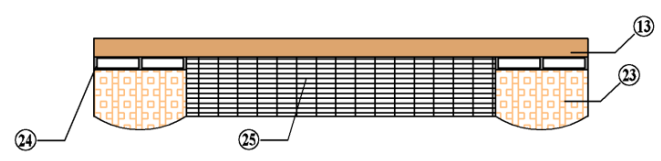

c)

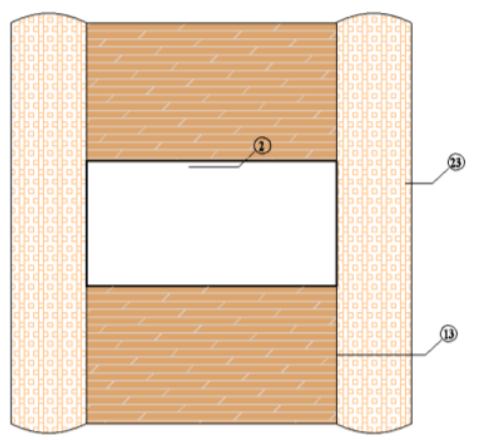

b)

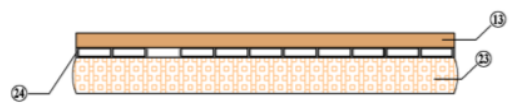

d)

Fig. 6. Floating platform

a) Section 1-1; b) Section 2-2; c) Section 3-3; d) Section 4-4. 
The air module and the submersible module can operate together or separately, depending on the existing natural conditions.

\subsubsection{Mode of operation}

Wind energy, solar energy and hydraulic energy resulted from the movement of water are captured separately by a smart system and converted into electricity, which is stored and distributed to the consumer. Because the complex system uses three sources of renewable energy production of different nature, the operation can be continuous, regardless of weather conditions. If the weather conditions are unfavorable for one of the sources, the energy is still captured from the other two sources.

The power of the complex renewable energy production facility from three sources depends on the size of the designed facility and the renewable energy potential of the area where the facility is located.

\subsubsection{Slot-deflector system}

Because the turbine rotor of the two modules is intubated, the role of the deflectors as well as the slot-deflector system are very important in order to increase the efficiency of the installation. The deflectors have the role of directing and concentrating the current of air or water towards the turbine blades or the paddles. The angle of entry of the air flow through the slots can vary depending on the weather conditions, thus obtaining maximum efficiency for the given conditions. The slot-deflector system is inspired by the profile of some birds' wings during flight, being a bioengineering adaptation [8]. The initial module had 16 slots, with the same number of deflectors. After numerical modeling and laboratory tests, the number of slots was reduced to 8, with a larger opening, which allowed the use of larger width deflectors, which better directed and concentrated the airflow in the slot-deflector system [8]. 


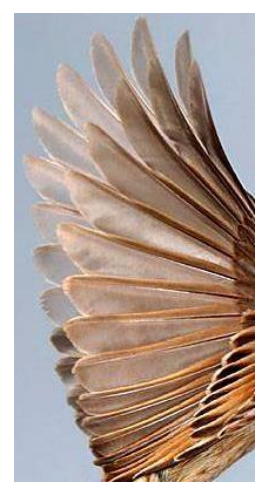

Fig. 7. The profile of the bird wing in flight

\subsection{Optimizing the efficiency of air module blades by applying a bioengineering solution}

The aerial module was initially equipped, in patented form, with 8 rows of trapezoidal blades (Fig. 5). Another type of blade was tested, according to the bioengineering model of the Rhus typhina seed (Fig. 8), an invention submitted to the State Office for Inventions and Trademarks, in November 2018 [9].
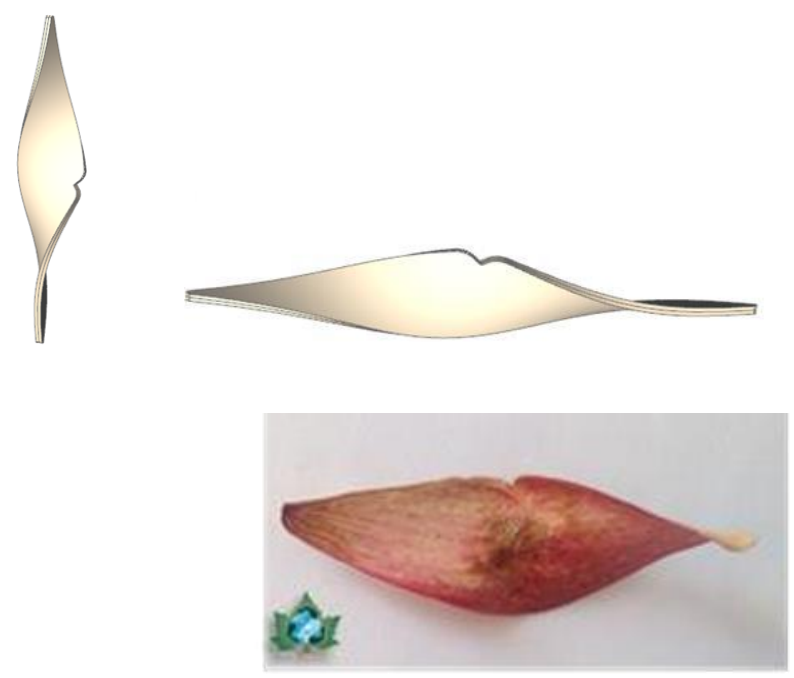

Fig. 8. The bioengineering model of the Rhus typhina seed used as model for blades and paddles 
This model was made and tested in two versions: the turbine axis equipped with 8 blades on one floor and equipped with 8 blades on two floors [10]. The second version (Fig. 9) showed a higher yield in free regime.

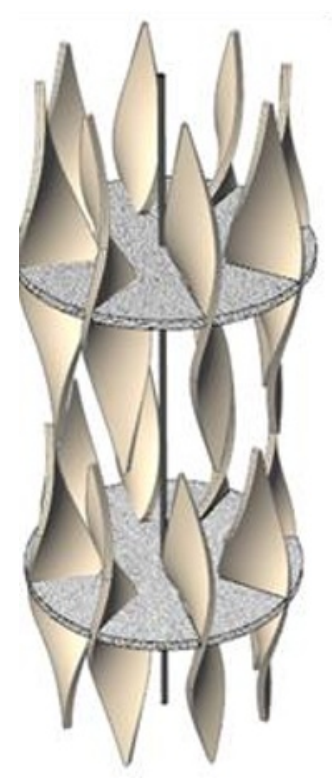

Fig. 9. Two-stage axis of the air module equipped with blades according to the bioengineering model of the Rhus typhina seed

\subsection{Optimization of the partially submerged module by changing the geometry of the paddles}

The researches started with the partially submerged module, part of the initial patented complex installation, which was admitted for funding, within the project with the acronym TEACHERS. Initially, before patenting, the module was equipped with rectangular paddles, on the central axis being 6 paddles of this geometry.

The optimizing stages of the blades shape to increase their performance were the following:

1. In the first stage of the researches it was highlighted that following the laboratory experiments the movement of the rotor of the hydraulic turbine was not continuous, but it had a moment in which the water current was no 
captured by the paddle, being created a moment of inertia which stopped the movement.

2. In order to eliminate this syncope, two paddles were attached to the axis, so that 8 paddles were provided in total (Fig. 10). Laboratory experiments have shown that the problem initially reported has been resolved in this way.
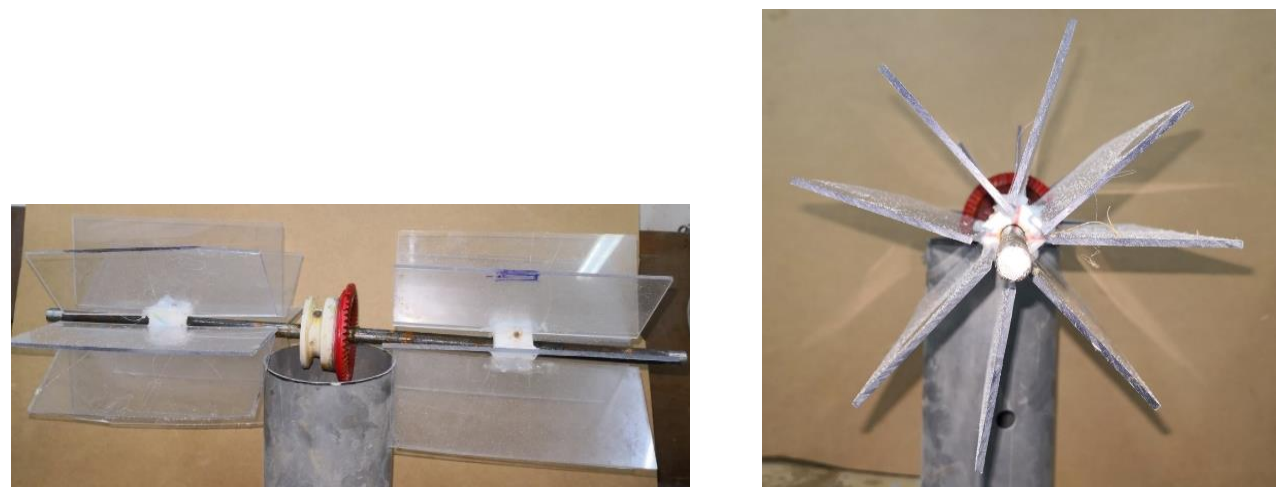

Fig. 10. The axis with 8 rectangular paddles from the optimized submersible module.

Longitudinal view and cross-sectional view

3. In the third stage of the researches, the 8 rectangular paddles were twisted, according to the bioengineering model of DNA, thus changing the contact angle between water and paddles (Fig. 11)
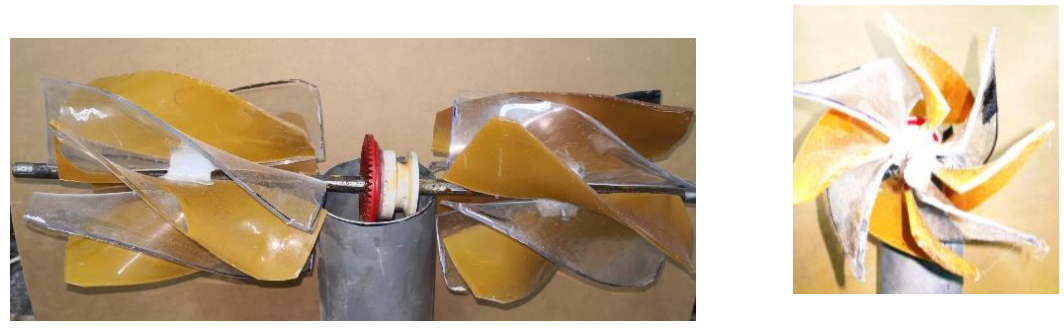

Fig. 11. The axis with 8 rectangular-shaped paddles, which were twisted, according to the bioengineering model of DNA. Longitudinal view and cross-sectional view 
4. In the last stage of the researches, paddles inspired by the bioengineering model of the Rhus typhina seed were tested and the performance of some paddles (similar to that of the blades) was evaluated by laboratory tests and measurements, both inspired by the bioengineering model of Rhus typhina seed, the geometry of the paddles being patented [9]. On the axis were also disposed 8 paddles, as it is presented in figure 12 [11].
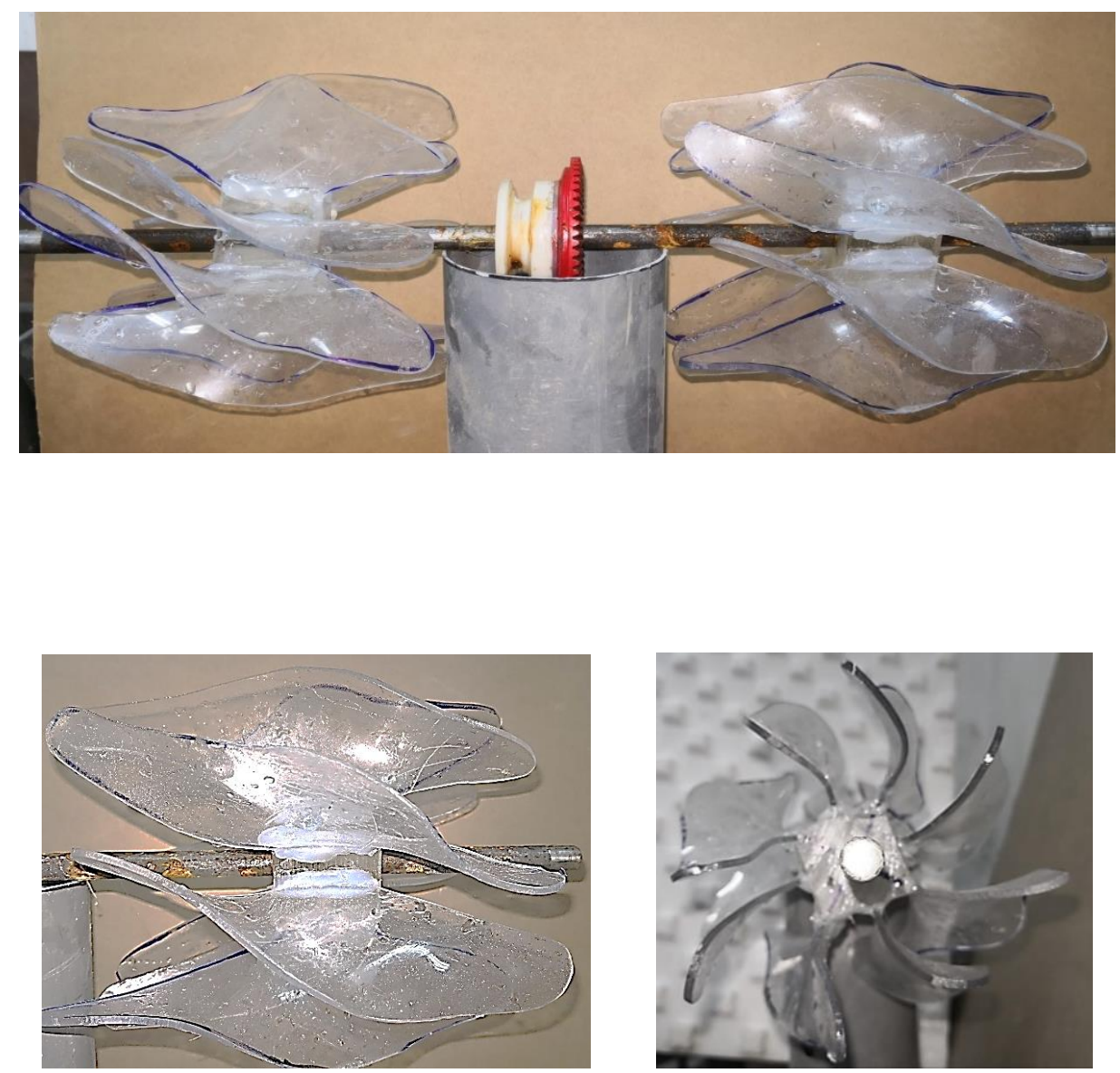

Fig. 12. The axis with 8 paddles in the shape of a Rhus typhina seed. Longitudinal view, detail and cross-sectional view 


\section{Results and discussions}

\subsection{Optimizing the efficiency of the air module blades}

The tests were performed for 3 airflow velocities: $1.5 \mathrm{~m} / \mathrm{s}, 1.8 \mathrm{~m} / \mathrm{s}$ and 2.4 $\mathrm{m} / \mathrm{s}$, the results being listed in Table 1 .

Table 1. Values resulting from air mode testing.

\begin{tabular}{|lccc|}
\hline & \multicolumn{3}{c}{$\begin{array}{c}\text { Blades rotation speed [rot/s] / } \\
\text { Blade type }\end{array}$} \\
Scenarios & $\begin{array}{c}\text { Air flow velocity } \\
{[\mathrm{m} / \mathrm{s}]}\end{array}$ & $\begin{array}{c}\text { Trapesoidal } \\
\text { blade }\end{array}$ & $\begin{array}{c}\text { Bioengineering } \\
\text { model }\end{array}$ \\
& & & \\
\hline & & & \\
\hline $\mathbf{1}^{\text {st }}$ scenario & 1.5 & 1.20 & 2.10 \\
\hline $\mathbf{2}^{\text {nd }}$ scenario & 1.8 & 1.87 & 2.46 \\
\hline $\mathbf{3}^{\text {rd }}$ scenario & 2.4 & 2.57 & 3.60 \\
\hline
\end{tabular}

The table reveals that the blades having as bioengineering model the Rhus typhina seed substantially improved the efficiency of the rotor in free regime, for all tested air current velocities. The most significant increase was obtained at low velocity $(+75 \%)$, followed by maximum and average airflow velocities, with comparable values $(+40 \%$ and $+32 \%$, respectively).

\subsection{Optimizing the efficiency of the submersible module paddles}

The tests were performed for 2 water flow velocities: $0.5 \mathrm{~m} / \mathrm{s}$ and 1 $\mathrm{m} / \mathrm{s}$, according to the table below. 
Table 2. Values resulting from mode testing.

\begin{tabular}{|c|c|c|c|}
\hline & Paddle type & $\begin{array}{l}\text { Water velocity } \\
(\mathrm{m} / \mathrm{s})\end{array}$ & Rotations/minute \\
\hline \multirow[t]{2}{*}{1} & \multirow{2}{*}{ Initial rectangular paddles } & 0.5 & 14 \\
\hline & & 1.0 & 18 \\
\hline \multirow[t]{2}{*}{2} & \multirow{2}{*}{ Twisted rectangular paddles } & 0.5 & 16 \\
\hline & & 1.0 & 24 \\
\hline \multirow[t]{2}{*}{3} & \multirow{2}{*}{$\begin{array}{l}\text { Paddles following the Rhus typhina } \\
\text { seed model }\end{array}$} & 0.5 & 20 \\
\hline & & 1.0 & 30 \\
\hline
\end{tabular}

The table shows a clear improvement in the efficiency of the paddles with the geometry adapted to the Rhus typhina seed (by $43 \%$ more rotations per minute, at a water flow rate of $0.5 \mathrm{~m} / \mathrm{sec}$, respectively $67 \%$ more rotations per minute, at a water flow rate of $1.0 \mathrm{~m} / \mathrm{sec}$ ), compared to the initial rectangular paddles. Regarding the twisted rectangular paddles, they showed for the tested water velocities, lower yields than the paddles with geometry adapted to the Rhus typhina seed, but higher compared to the initial paddles (by $14 \%$ for the water velocity of $0.5 \mathrm{~m} / \mathrm{s}$, respectively $33 \%$ for the water velocity of $1 \mathrm{~m} / \mathrm{s}$ ).

\section{Conclusions}

In order to increase the renewable energy production in the EU to almost a third of total energy, it is necessary to develop viable solutions for the use of this type of clean energy with low environmental impact and higher efficiency. In the same time, it is necessary to ensure renewable energy in areas hard to reach by conventional energy networks, but which have important natural potential.

The complex installation presented in this paper has the following attributes: First, it integrates 3 natural sources of electricity production: wind energy, solar energy and hydraulic energy of water current; Second, it can be located on flowing waters which offers favorable conditions for the natural energy potential, but which can also be an energy alternative for hard to reach areas located along watercourses.

The researches presented in this paper had as a starting point a patented concept and aimed to improve the efficiency of the turbines of the complex installation in order to increase its efficiency. Thus, for both the wind 
turbine and the hydraulic turbine, new geometries of the blades and paddles inspired by nature were tested. The yields obtained were higher than the initial ones, as follows:

- For the blades having as bioengineering model the Rhus typhina seed, higher values were obtained, with up to $75 \%$, for all 3 tested velocities of the air current;

- For paddles with bioengineering models, Rhus typhina seed and DNA model were obtained higher values by up to $67 \%$, at a water flow velocities of $1 \mathrm{~m} / \mathrm{s}$, for Rhus typhina seed model, respectively 33\% for the DNA model at the same velocity.

The research results have shown, once again, that nature offers a variety of bioengineering solutions that can be applied to achieve and/or to improve the efficiency of engineering installations or products.

Acknowledgment: This work was supported by a grant from the Romanian Ministry of Education and Research, CCCDI - UEFISCDI, project number PN-III-P1-1.2-PCCDI-2017-0406/Innovative technologies for the production of renewable energy from natural sources integrated in complex installations - TEACHERS, within PNCDI III.

\section{References}

1. Directive (EC) No 2018/2001 of the European Parliament and of the Council of 11 December 2018 on the promotion of the use of energy from renewable sources (recast), (2018)

2. G. Poteras, G. Deák, A.F. Nicolae, I Neacsu, N.S. Raischi, patent no. 131456, Floating installation for the production of electricity from multiple renewable sources, (2018)

3. National Institute for Research and Development in Environmental ProtectionINCDPM, project no. PCDDI 81/2018 Innovative Technologies for Renewable Energy Production from Integrated Natural Sources in Complex Installations - TEACHERS, (2018)

4. I. Dincer, Y. Bicer, Integrated Energy Systems for Multigeneration, ScienceDirect, 143-221, (2020)

5. Hybrid renewable energy turbine using wind and solar power, Pattent no. US 8330296 B2, Unites States, (2012)

6. A. Barata da Rocha, M. Macieira, F, Gomes Almeida, A, Torres Marques, PT 109985, Dispositivo de conversão da energia das ondas, (2018)

7. G. Poteraș, G. Deak, A.G. Baraitaru, M.V. Olteanu, N.S. Raischi, Bioengineering technologies used for the development and equipment of complex installationsto obtain energy from three renewable sources. complex installations for coastal areas, ICONGEET, (2020)

8. G. Poteras, G. Deák, C. Sirbu, N.S. Raischi, M.V. Olteanu, Conferință internațională de inginerie electrică ICPE-CA „Structuri, Materiale și Sisteme Electrice Avansate” ASMES, (2019)

9. G. Poteraș, G. Deák, A.F. Nicolae, A.I. Dăescu, I.F. Burlacu, I. Neacșu, Cerere brevet de invenție, Pale cu geometrii inspirate după un model bioingineresc pentru turbine eoliene şi hidraulice, (2018) 
10. G. Poteras, A.F. Nicolae, A.I. Dăescu, I.F. Burlacu, S.A. Zamfir, International Conference on Renewable Energy and Environment Engineering in Paris, France, (REEE 2018), (2018)

11. G. Poteraş, Gy. Deák, M.V. Olteanu, I.F. Burlacu, C. Sîrbu, International Conference on Renewable Energy and Environment Engineering in Munchen, Germany, (REEE 2019), (2019) 